\title{
Update on treatment of follicular non-Hodgkin's lymphoma: focus on potential of bortezomib
}

\author{
This article was published in the following Dove Press journal: \\ Patient Preference and Adherence \\ 22 March 2012 \\ Number of times this article has been viewed
}

\section{Danielle M Brander Anne W Beaven}

Duke University Medical Center, Durham, NC, USA
Correspondence: Danielle M Brander DUMC Box 384I, Durham, NC 277I0, USA

Fax + I 9196843309

Email danielle.brander@dm.duke.edu
Abstract: Follicular lymphoma is predominantly managed as a chronic disease, with intermittent chemo/immunotherapy reserved for symptomatic progression. It is considered incurable with conventional treatments, and current therapeutic options are associated with significant toxicities that are especially limiting in older patients. Bortezomib (PS-341; Velcade ${ }^{\circledR}$ ), a first-in-class drug targeting the proteolytic core subunit of the $26 \mathrm{~S}$ proteasome, has emerged as a therapeutic alternative in follicular lymphoma, with promising preclinical data and efficacy in patients with other hematological malignancies. Several clinical trials were conducted with bortezomib for the treatment of non-Hodgkin's lymphoma. As a single agent, overall responses in follicular lymphoma varied greatly $(16 \%-41 \%)$, with weekly bortezomib showing less neurotoxicity than twice-weekly regimens, but with concern about decreased responses. Combination with rituximab was projected to improve the efficacy of bortezomib, but this resulted in increased toxicities and questionable added benefit. Although the largest Phase III study in follicular lymphoma of bortezomib plus rituximab versus rituximab alone demonstrated a significant progressionfree survival difference, the absolute difference was small (12.8 months versus 11 months). Combining bortezomib with established regimens, such as rituximab plus cyclophosphamide, doxorubicin, vincristine, and prednisone (R-CHOP), rituximab, cyclophosphamide, vincristine, and prednisone (R-CVP), or rituximab-bendamustine also did not show definite benefit, and many of these studies did not meet their primary endpoint when bortezomib failed to improve responses or survival to the degree anticipated. In a disease where the goal of treatment is palliative and affected patients often have other medical and treatment-related comorbidities, decisions regarding therapies which carry risks of additional toxicities must be considered carefully. Conclusive evidence of the ability of bortezomib to improve patient outcomes meaningfully and to justify the added toxicity is lacking, but limitations in cross-trial comparisons are recognized. Large randomized trials and investigations of combinations with promising novel targeted agents will aid in determining the role of bortezomib, if any, in the future treatment of follicular lymphoma.

Keywords: bortezomib, follicular lymphoma, proteasome inhibitor

\section{Introduction}

Follicular lymphoma, an indolent lymphoma of germinal center B cells, is the second most common subtype of non-Hodgkin's lymphoma in the United States, with nearly 14,000 new cases diagnosed annually. ${ }^{1,2}$ Patients typically present with asymptomatic enlarged superficial lymph nodes or nonspecific complaints from bulky deeper lymph nodes, but unusual presentations with primary involvement of the gastrointestinal tract, ${ }^{3,4}$ skin, or other extranodal sites have been described..$^{5}$ A minority of patients with follicular lymphoma are diagnosed with early stage I/II disease and may be cured 
by radiotherapy..$^{6-8}$ However, nearly $70 \%-85 \%$ of patients will present with advanced disease, including lymphatic involvement on both sides of the diaphragm (Stage III), or diffuse involvement of extralymphatic tissues (Stage IV). Asymptomatic patients with stable disease can be observed closely without treatment, given insufficient evidence at present to indicate a survival advantage for early intervention, ${ }^{9-11}$ but a majority of patients will eventually need therapy. Despite persistent progress in available chemotherapy and immunotherapy, follicular lymphoma is still considered incurable by conventional treatment.

Follicular lymphoma is managed as a chronic disease, with patients intermittently requiring therapy for symptomatic progression of disease. When patients relapse, treatment options include observation for asymptomatic patients, immunotherapy alone (ie, rituximab), immunotherapy with combination chemotherapy, radioimmunotherapy (conjugate antibody with radioisotope), or, rarely, autologous or allogeneic hematopoietic cell transplantation. If available, enrollment in a clinical trial is the preferred option. Each choice of therapy has varying degrees of toxicities with associated effects on quality of life and risk of treatment-related death. Considering the median age at diagnosis is $61-63$ years, ${ }^{1,12}$ these risks can limit treatment options in a population with medical comorbidities and functional impairment. In addition, as overall survival in follicular lymphoma increases, ${ }^{13}$ significant concerns are emerging regarding long-term cumulative toxicities from treatment. These limitations create a need for the development of well tolerated, novel, targeted therapeutic options for relapsed follicular lymphoma.

The proteasome inhibitors have become an area of active research in the treatment of non-Hodgkin's lymphoma. Bortezomib (PS-341; Velcade ${ }^{\circledR}$, Millennium Pharmaceuticals Inc, Cambridge, MA) was the first proteasome inhibitor to be approved by the US Food and Drug Administration, initially for use in multiple myeloma and later in relapsed mantle cell lymphoma. ${ }^{11-13}$ Its mechanism of action, especially its potential effect on B cell lymphoma 2 (Bcl-2) led bortezomib to become a favorable candidate for exploration as a single agent or as part of combination therapy for relapsed follicular lymphoma.

\section{Bortezomib: mechanism of action}

Bortezomib was a first-in-class drug designed to target the ubiquitin-proteasome pathway, the regulatory pathway for intracellular protein degradation in eukaryotes. Specifically, bortezomib is a potent boronic acid inhibitor of the $20 \mathrm{~S}$ proteolytic core subunit of the $26 \mathrm{~S}$ proteasome.
Ubiquitinized ("tagged") proteins are targeted for destruction by the proteasome; these tagged substrates can include cyclins and cyclin-dependent kinases, transcription factors, tumor suppressors (ie, p53), and misfolded or adversely mutated proteins. The timed destruction of these key regulatory proteins enables cells (normal or neoplastic) to control cell viability, proliferation, cell cycle progression, and in the case of malignancy, the ability to metastasize through expression of genes involved in migration, angiogenesis, and adhesion. ${ }^{14-16}$ Because of the role of the ubiquitin-proteasome pathway in cell survival, proteasome inhibition is proposed to have powerful antineoplastic properties by both preventing tumor growth and metastasis, and increasing apoptosis of the malignant clone. ${ }^{15}$

The first preclinical studies involving PS-341 (bortezomib) were conducted in a wide variety of cell lines and murine models, including solid tumors (prostate, breast, lung) and hematologic malignancies, and confirmed its ability to target the proteasome with resultant cell cytotoxicity, as well as arrest of cell cycle progression leading to subsequent apoptosis. ${ }^{17-19}$ Additional in vitro and in vivo studies demonstrated an antagonistic effect of proteasome inhibitors on specific controllers of apoptosis, including nuclear factor kappa B (NF-кB), Bcl-2, and caspases. ${ }^{15}$

Bcl-2, an antiapoptotic protein, is overexpressed in approximately $85 \%$ of cases of follicular lymphoma as a result of the $t(14 ; 18)$ translocation characteristic of this malignancy, thereby making $\mathrm{Bcl}-2$ an interesting target for proteasome inhibitors. ${ }^{20,21}$ In vitro work demonstrated that cell lines treated with proteasome inhibitors induced phosphorylation and degradation of Bcl-2, therefore preventing the protective function of the protein with resultant apoptosis. ${ }^{22,23} \mathrm{NF}-\kappa \mathrm{B}$ is another transcription factor that controls expression of genes involved in proliferation and inhibition of apoptosis in part by downstream activation of the Bcl-2 family. It can be constitutively activated in hematologic malignancies or accumulate in chemotherapytreated patients as a mechanism of drug resistance and so is another exciting target in the treatment of non-Hodgkin's lymphoma. ${ }^{24,25}$ Proteasome inhibition can stabilize the intracellular inhibitor of NF- $\mathrm{BB}, \mathrm{I} \kappa \mathrm{B}$, thereby abrogating the deleterious effects of NF- $\mathrm{KB}$ on proliferation, cell adhesion, angiogenesis, and resistance to inducers of apoptosis. ${ }^{14,26}$ Considering the classic pathobiology of disordered apoptosis in indolent lymphomas, these targets have been of particular interest in follicular lymphoma, and provided support for the promising therapeutic potential for bortezomib and other proteasome inhibitors. 


\section{Single-agent clinical trials}

As bortezomib gained promise in the hematologic malignancies for its treatment of refractory multiple myeloma, trials of its use in the non-Hodgkin's lymphomas were progressing. Early Phase II studies of singleagent bortezomib in relapsed/refractory non-Hodgkin's lymphoma revealed strikingly varied efficacy, in that chronic lymphocytic leukemia was almost uniformly refractory to bortezomib, while mantle cell lymphoma demonstrated exciting responses that eventually led to its approval by the US Food and Drug Administration for mantle cell lymphoma. In most studies, the results for the other lowgrade lymphomas, including follicular lymphoma, were less impressive (summarized in Table 1). ${ }^{27-30}$ The demonstrated differences in response rates between mantle cell lymphoma and other non-Hodgkin's lymphoma, especially considering the established inferior overall survival and fewer effective chemotherapeutic and/or immunotherapeutic options in mantle cell lymphoma, led many to describe patients with mantle cell lymphoma separately from other patients with non-Hodgkin's lymphoma. Therefore, our discussion of the bortezomib trials reflects this separation of patients with mantle cell lymphoma.
One of the first studies of single-agent bortezomib in follicular lymphoma, published by Goy et al, was a multicenter study of 60 patients with relapsed or refractory non-Hodgkin's lymphoma (median 3.5 prior therapies). The majority of patients had mantle cell lymphoma $(n=33)$. Patients were treated with bortezomib $1.5 \mathrm{mg} / \mathrm{m}^{2}$ on days 1 , 4,8 , and 11 of a 21 -day cycle. Although the overall response rate of $44 \%$ in the mantle cell lymphoma arm was encouraging, only $19 \%$ of the "other" patients with non-Hodgkin's lymphomas responded; results were not specifically reported for the five patients with follicular lymphoma who were enrolled in the study. ${ }^{28}$

Another Phase II trial reported the following year, ie, the multicenter European trial by Strauss et al, was designed to assess the efficacy of single-agent bortezomib in patients with non-Hodgkin's lymphoma. Fifty-one patients were enrolled, including 13 patients with follicular lymphoma. Patients were treated at a lower dose $\left(1.3 \mathrm{mg} / \mathrm{m}^{2}\right)$ of bortezomib on days 1 , 4,8 , and 11 of a 21-day cycle. Responses occurred in two of the patients with follicular lymphoma (overall response rate $18 \%$ ), but were not seen until follow-up imaging 3 months after conclusion of bortezomib treatments. ${ }^{30}$ Similar results were found by Di Bella et al in a multicenter Phase II trial of

Table I Clinical trials of single-agent bortezomib

\begin{tabular}{|c|c|c|c|c|}
\hline \multirow[t]{2}{*}{ Population } & \multirow[t]{2}{*}{ Dosing schedule } & \multirow[t]{2}{*}{ Response rates in FL } & \multicolumn{2}{|c|}{ Toxicities reported as percentage of all patients } \\
\hline & & & Neuropathy & Other adverse events \\
\hline Relapsed/refractory & Biweekly: & ORR: NR & Gr $3 / 4$ neuropathy: 5\% & Gr $3 / 4$ neutropenia: $15 \%$ \\
\hline indolent B cell & bortezomib & CR/CRu: NR & & Gr $3 / 4$ thrombocytopenia: $49 \%$ \\
\hline $\begin{array}{l}\text { NHL and } M C L \\
n=60\left(8 \% \mathrm{FL}^{*}\right)\end{array}$ & $\begin{array}{l}1.5 \mathrm{mg} / \mathrm{m}^{2} \mathrm{~d} \mathrm{I}, 4,8, \\
\text { and II of } 2 \mathrm{I}-\mathrm{d} \text { cycle }\end{array}$ & & & Gr 3/4 GI toxicity: $22 \%$ \\
\hline \multicolumn{5}{|l|}{ Goy et $\mathrm{al}^{28}$} \\
\hline Relapsed/refractory & Biweekly: & ORR: $77 \%$ & Gr $3 / 4$ neuropathic pain: $0 \%$ & Gr $3 / 4$ neutropenia: $4 \%$ \\
\hline indolent $\mathrm{NHL}$ and $\mathrm{MCL}$ & bortezomib & CR/CRu: $22 \%$ & Gr $3 / 4$ neuropathy (sensory): $8 \%$ & Gr $3 / 4$ thrombocytopenia: $27 \%$ \\
\hline $\mathrm{n}=26(38 \% \mathrm{FL})$ & $1.5 \mathrm{mg} / \mathrm{m}^{2} \mathrm{~d} \mathrm{I}, 4,8$ & & & Gr 3/4 Gl toxicity: 3\% \\
\hline O'Connor et al' ${ }^{29}$ & and $I I$ of $2 I-d$ cycle & & & \\
\hline Relapsed/refractory & Biweekly: 1.3 mg/m² & ORR: $18 \%$ & Gr $3 / 4$ neuropathic pain: $4 \%$ & Gr $3 / 4$ neutropenia: $10 \%$ \\
\hline lymphoma & on $\mathrm{d} \mathrm{I}, 4,8$, and $\mathrm{II}$ & (All FL responses were & Gr 3/4 neuropathy (sensory): $2 \%$ & Gr $3 / 4$ thrombocytopenia: $43 \%$ \\
\hline $\mathrm{n}=5 \mathrm{I}(25 \% \mathrm{FL})$ & of a 2 I-d cycle & late PRs occurring & Gr $3 / 4$ autonomic dysfunction: $4 \%$ & Gr 3/4 GI toxicity: 16\% \\
\hline \multirow[t]{3}{*}{ Strauss et $\mathrm{al}^{30}$} & & 3 months s/p & & \\
\hline & & bortezomib) & & \\
\hline & & CR/CRu: $0 \%$ & & \\
\hline Relapsed/refractory & Biweekly: 1.3 mg/m² & ORR: $17 \%$ & Gr 3/4 neuropathy: 7\% & Gr $3 / 4$ neutropenia: $8 \%$ \\
\hline indolent NHL & d I, 4, 8 and II & CR/CRu: $8 \%$ & & Gr $3 / 4$ thrombocytopenia: $20 \%$ \\
\hline$n=53(68 \% F L)$ & of a $21-d$ cycle & & & Gr 3/4 Gl toxicity: 15\% \\
\hline \multicolumn{5}{|l|}{ Di Bella et $\mathrm{al}^{31}$} \\
\hline FL or MCL with & Weekly: 1.8 mg/m² & ORR: I4\% & Gr 3/4 neuropathy (sensory): $4 \%$ & Gr $3 / 4$ neutropenia: $15 \%$ \\
\hline$\leq 3$ prior therapies & on $\mathrm{d} \mathrm{I}, 8, \mathrm{I} 5$, and 22 & CR/CRu: $0 \%$ & & Gr 3/4 thrombocytopenia: $8 \%$ \\
\hline$n=26(65 \% \mathrm{FL})$ & of a $35-d$ cycle & & & Gr 3/4 Gl toxicity: 0\% \\
\hline Gerecitano et $\mathrm{al}^{33}$ & & & & \\
\hline
\end{tabular}

Note: *Includes five patients with FL and three patients with transformed FL.

Abbreviations: FL, follicular lymphoma; NHL, non-Hodgkin lymphoma; $\mathrm{MCL}$, mantle cell lymphoma; ORR, overall response rate; CR/CRu, complete response/unconfirmed complete response; Gr, grade; d, day; GI, gastrointestinal; NR, not reported. 
single-agent bortezomib at the $1.3 \mathrm{mg} / \mathrm{m}^{2}$ dose on the same twice-weekly schedule for relapsed or refractory indolent lymphoma. Thirty-six patients with follicular lymphoma were enrolled, and for this subgroup the overall response rate was $17 \%$, with one confirmed complete response and one unconfirmed complete response, as well as three partial responses. ${ }^{31}$ This was the largest of the single-agent trials, by both total number of patients and number of patients with follicular lymphoma, and it was the first to report time to progression, with a median time to progression for all patients of 5.1 (range 0.2-27.7) months.

Much higher response rates were found by O'Connor et al using $1.5 \mathrm{mg} / \mathrm{m}^{2}$ twice weekly for 2 weeks followed by a 1-week break. ${ }^{29,32}$ Eighteen subjects with follicular lymphoma were evaluable for response, with an overall response rate of $50 \%$ and a complete response of $22 \%$, similar to the results seen in mantle cell lymphoma. However, the time to treatment response was significantly longer in the follicular lymphoma group, with a median time to treatment response of 11 weeks versus only 4 weeks in mantle cell lymphoma. Overall, the median number of cycles received on this trial was three, and this may explain the higher response rates seen in this trial than in the Goy trial, in which nonresponding subjects were taken off study after only two cycles of bortezomib. More treatment cycles cannot entirely explain the increased responses seen by O'Connor et al, because a median of 3-4 cycles was administered in the trials reported by Di Bella et al and Strauss et al with less impressive results. However, the latter two trials used a lower dose of bortezomib $\left(1.3 \mathrm{mg} / \mathrm{m}^{2}\right.$ versus $\left.1.5 \mathrm{mg} / \mathrm{m}^{2}\right)$, which could have contributed to the lower response rates. ${ }^{30,31}$

Although bortezomib was generally well tolerated, side effects did lead to drug discontinuation. As many as $33 \%$ of subjects in the clinical trials discontinued the drug due to adverse events, ${ }^{31}$ even with the lower bortezomib dose of $1.3 \mathrm{mg} / \mathrm{m}^{2}$. Therefore, in an effort to ameliorate toxicities, a weekly bortezomib schedule was again studied by Gerecitano et al. ${ }^{33}$ Bortezomib at $1.8 \mathrm{mg} / \mathrm{m}^{2}$ was given for 4 consecutive weeks, followed by a 2 -week break for each cycle. Twenty-six patients were treated, including 17 patients with follicular lymphoma. Less toxicity occurred with weekly dosing, but response rates were lower than expected. The overall response rate was only $14 \%$ in the 14 assessable follicular lymphoma patients, with no complete responses. The overall response rate for all 22 evaluable lymphoma patients enrolled was only $18 \%$. This was significantly less than the overall response rate of
$50 \%$ obtained by the same investigators in the clinical trial of biweekly bortezomib discussed above..$^{29}$ Progression-free survival was not different at 4.8 months for twice-weekly patients and 6.7 months for weekly patients. ${ }^{33}$

The weekly versus twice-weekly debate was definitively answered by the Groupe d'Etude Des Lymphomas De l'Adulte (GELA) in a randomized Phase II trial comparing single-agent bortezomib on a weekly or biweekly schedule in 87 patients with relapsed or refractory follicular lymphoma. Subjects were randomized to arm A, ie, $1.5 \mathrm{mg} / \mathrm{m}^{2}$ bortezomib administered on days $1,4,8$, and 11 of a 21-day cycle for eight cycles, or to arm $\mathrm{B}$, ie, $1.6 \mathrm{mg} / \mathrm{m}^{2}$ bortezomib administered weekly on days $1,8,15$, and 22 of a 35-day cycle for six cycles. A predefined interim efficacy analysis demonstrated insufficient response in the weekly dosing arm, so it was closed to enrollment. Overall response rates were reported as $32 \%$ in arm A and $23 \%$ in arm B, ${ }^{34}$ so twice-weekly bortezomib was recommended for further study. However, given the low overall response rates from single-agent bortezomib in follicular lymphoma, the focus had already shifted toward the combination of bortezomib with rituximab or other chemoimmunotherapy in the hope of improving the efficacy of bortezomib in follicular lymphoma.

\section{Bortezomib plus rituximab}

Bortezomib plus rituximab was an attractive area of study because of the differing mechanisms of action and different side effect profiles, and demonstrated single-agent activity for both agents in follicular lymphoma. In vitro and in vivo murine studies demonstrated additive effects on response from the combination of bortezomib and the anti-CD20 monoclonal antibody, rituximab. ${ }^{35-37}$ In addition, a mantle cell lymphoma murine model showed statistically significant improvement in overall survival in mice treated with bortezomib + rituximab compared with mice that received either drug alone, although no specific data were available in mice with follicular lymphoma. ${ }^{37}$ It has been hypothesized that bortezomib may overcome rituximab resistance by upregulating CD20 expression in rituximabresistant patients characterized by low CD20 expression. ${ }^{38}$ Based on the preclinical data, results from trials of bortezomib plus rituximab were anticipated not only for the response potential in patients with relapsed or refractory non-Hodgkin's lymphoma, but also in the hope of a less toxic alternative to conventional chemotherapies. Selected bortezomib plus rituximab combination trials are represented in Table 2.

One of the first studies of this combination again examined the weekly versus twice-weekly bortezomib schedule, 
Table 2 Clinical trials of bortezomib in combination with rituximab

\begin{tabular}{|c|c|c|c|c|}
\hline \multirow[t]{2}{*}{ Population } & \multirow{2}{*}{$\begin{array}{l}\text { Bortezomib dosing } \\
\text { schedule }\end{array}$} & \multirow[t]{2}{*}{ Response in FL pts } & \multicolumn{2}{|c|}{ Toxicities reported as percentage of patients } \\
\hline & & & Gr 3/4 neuropathy & Other AEs (GR 3/4) \\
\hline $\mathrm{RCT}$ : relapsed/refractory & Arm A: biweekly & ORR: $48 \%$ & Neuropathy & Neutropenia: $10 \%$ \\
\hline FL or MZL & bortezomib $1.3 \mathrm{mg} / \mathrm{m}^{2}$ & & NOS: $10 \%$ & Thrombocytopenia: 10\% \\
\hline $\mathrm{n}=8 \mathrm{I}$ & $n=41$ & & & Gl toxicity: $27 \%$ \\
\hline (86\% FL) & Arm B: weekly & ORR: $37 \%$ & Neuropathy & Neutropenia: $3 \%$ \\
\hline \multirow[t]{2}{*}{ de Vos et al ${ }^{36}$} & bortezomib $1.6 \mathrm{mg} / \mathrm{m}^{2}$ & & NOS: $5 \%$ & Thrombocytopenia: $0 \%$ \\
\hline & $\mathrm{n}=40$ & & & Gl toxicity: $20 \%$ \\
\hline $\mathrm{RCT}$ : relapsed/refractory & Arm A: biweekly & ORR for all tumor types & Neuropathy & Neutropenia: $24 \%$ \\
\hline $\mathrm{FL}, \mathrm{MCL}$, or $\mathrm{WM}$ & bortezomib $1.3 \mathrm{mg} / \mathrm{m}^{2}$ & $67 \%$ in each arm; & NOS: $14 \%$ & Thrombocytopenia: $29 \%$ \\
\hline$n=42(31 \% \mathrm{FL})$ & $\mathrm{n}=2 \mathrm{l}$ & ORR $53 \%$ for FL & & GI toxicity: $15 \%$ \\
\hline \multirow[t]{4}{*}{ Agathocleous et $\mathrm{al}^{39}$} & & (ORR for FL per arm NR) & & \\
\hline & Arm B: weekly & & Neuropathy & Neutropenia: $14 \%$ \\
\hline & bortezomib 1.6 mg/m² & & NOS: $5 \%$ & Thrombocytopenia: $10 \%$ \\
\hline & $\mathrm{n}=2 \mathrm{l}$ & & & Gl toxicity: $0 \%$ \\
\hline Relapsed/refractory & Biweekly & ORR: $55 \%$ & Neuropathy (sensory): $36 \%$ & Neutropenia: $20 \%$ \\
\hline $\mathrm{MCL}$ or $\mathrm{FL}$ & bortezomib* & CR/CRu: $45 \%$ & Neuropathy (motor): $4 \%$ & Thrombocytopenia: $20 \%$ \\
\hline$n=25$ (44\% FL) & $1.3-1.5 \mathrm{mg} / \mathrm{m}^{2}$ & PFS: II .5 mo & Autonomic neuropathy: $12 \%$ & GI toxicity: $0 \%$ \\
\hline \multicolumn{5}{|l|}{ Baiocchi et $\mathrm{al}^{41}$} \\
\hline $\mathrm{RCT}$ : relapsed/refractory & Weekly bortezomib & ORR: $63 \%$ & Neuropathy (sensory): $3 \%$ & Neutropenia: II\% \\
\hline $\mathrm{Gr} 1 / 2 \mathrm{FL}$ & 1.6 mg/m² d I, 8, 15 & CR/CRu: $25 \%$ & & Thrombocytopenia: $3 \%$ \\
\hline $\mathrm{n}=676 \mathrm{pts}(100 \% \mathrm{FL})$ & 22 of 35-day cycle & PFS: $12.8 \mathrm{mo}$ & & Gl toxicity: II\% \\
\hline \multirow[t]{5}{*}{ Coiffier et al ${ }^{42}$} & $37.5 \mathrm{mg} / \mathrm{m}^{2}$ & & & \\
\hline & $\mathrm{n}=336$ & & & \\
\hline & Rituximab only arm & ORR: $49 \%$ & Neuropathy (sensory): $0 \%$ & Neutropenia: $4 \%$ \\
\hline & $375 \mathrm{mg} / \mathrm{m}^{2}$ & CR/CRu: $18 \%$ & & Thrombocytopenia: $<1 \%$ \\
\hline & $\mathrm{n}=340$ & PFS: II mo & & Gl toxicity: $<1 \%$ \\
\hline
\end{tabular}

Notes: *After first II patients, the bortezomib dose was decreased from $1.5 \mathrm{mg} / \mathrm{m}^{2}$ to $1.3 \mathrm{mg} / \mathrm{m}^{2}$ because seven patients had Grade 3 neurotoxicity. No patients received preplanned rituximab-bortezomib maintenance therapy because of toxicity, <partial response to study drugs, or they proceeded to stem cell transplant. Gl toxicity may include diarrhea, nausea, constipation, and vomiting.

Abbreviations: Gl, gastrointestinal; RCT, randomized controlled trial; FL, follicular lymphoma; MZL, marginal zone lymphoma; MCL, mantle cell lymphoma; WM, Waldenstrom's macroglobulinemia; PFS, progression-free survival; ORR, overall response rate; CR/CRu, complete response/complete response unconfirmed; Gr, grade; AEs, adverse events; Pt, patient; d, day; NR, not reported; NOS, not otherwise specified; mo, months.

but this time in combination with rituximab. In 2009, de Vos et al reported a multicenter randomized Phase II study of weekly bortezomib $\left(1.6 \mathrm{mg} / \mathrm{m}^{2}\right)$ or twice-weekly bortezomib $\left(1.3 \mathrm{mg} / \mathrm{m}^{2}\right)$, each combined with rituximab for relapsed/refractory follicular lymphoma or mantle cell lymphoma. Seventy of the 81 patients enrolled had follicular lymphoma. The overall response rate for the patients with follicular lymphoma was $48 \%$ in arm A (twice-weekly bortezomib) and 39\% in arm B (weekly bortezomib). This higher response rate was seen in arm A, even though far fewer patients completed all protocol-driven therapy than in arm B (39\% versus $80 \%) .{ }^{36}$ Surprisingly, only a minority of discontinuations was attributed to adverse events $(10 \%$ in $\operatorname{arm} \mathrm{A}$ and $3 \%$ in arm B). The primary reasons for discontinuation of therapy were progressive disease (arm A, 24\%; $\operatorname{arm~B,~10\% )~or~patient/investigator~decision~(arm~A,~22\% ;~}$ $\operatorname{arm} \mathrm{B}, 5 \%$ ). However, it is possible that toxicities were the cause of some of the patient/investigator decisions to withdraw, because the incidence of grade $3 / 4$ adverse events
(54\% versus $35 \%)$ and the incidence of serious adverse events (29\% versus 15\%) were all higher on the biweekly ( $\operatorname{arm} \mathrm{A})$ regimen. These results suggest that, in combination with rituximab, weekly bortezomib was better tolerated, but with lower response rates than biweekly dosing.

In 2010, Agathocleous et al published their results of a Phase I/II multicenter trial in the UK also examining the regimen of rituximab with either twice-weekly ( $\operatorname{arm}$ A) or weekly (arm B) bortezomib in non-Hodgkin's lymphoma patients. After preliminary results from the other bortezomib trials discussed above, the trial proceeded directly to Phase II randomization after only seven patients were enrolled in the Phase I study. Though the randomized dosing regimens of weekly versus twice-weekly bortezomib mirrored the study by de Vos et al, the total number of cycles and the rituximab regimens differed slightly between the trials. A total of 42 patients were randomized to the Phase II study, including 13 patients with follicular lymphoma who demonstrated a histologic-specific overall 
response rate of $53 \% .{ }^{39}$ The overall response rate of all included patients was identical between the arms at $67 \%$, but the number of patients with follicular lymphoma was small, and differences in responses between arms for this subgroup were not reported. Unfortunately, toxicity was high, so only 14 of the 42 patients completed therapy as scheduled. The large majority of patients $(n=16)$ were discontinued from therapy for drug toxicities (eight for neuropathy and the remainder for either gastrointestinal toxicity, infection, fatigue, hemorrhage, or unspecified cardiac toxicity) or patient choice $(n=4)$. The remaining subjects withdrew because of disease progression $(n=7)$ or for an unknown reason in one patient. ${ }^{40}$

Baiocchi et al published a Phase II study using an induction regimen of rituximab plus twice-weekly bortezomib (initially $1.5 \mathrm{~m} / \mathrm{m}^{2}$ but decreased to $1.3 \mathrm{mg} / \mathrm{m}^{2}$ because of neurologic toxicity). The clinical trial included 25 patients with relapsed or refractory mantle cell lymphoma or follicular lymphoma. The overall response rate for the 11 patients with follicular lymphoma was 55\%, which was similar to the other studies of bortezomib plus rituximab. ${ }^{41}$ Although this was a small, nonrandomized, single-institution study, this trial was notable for interesting laboratory correlates. During cycle 1, subjects received bortezomib alone with the addition of rituximab during cycle 2 , so that the effects of rituximab on proteasome inhibition could be evaluated; they found no difference in proteasome inhibition with the addition of rituximab. There was also no correlation between levels of proteasome inhibition and response to the study drugs, although higher inhibition was associated with an increased incidence of grade 3 neurotoxicity. In contrast, when they evaluated Fc $\lambda$ gene polymorphisms (receptors which bind IgG antibodies) they found that subjects who were heterozygous for the CD32a genotype had significantly shorter progression-free survival compared with homozygotes. However, this was a small study and these findings would need to be confirmed in larger studies. The rate of grade $3 / 4$ neurotoxicity (54\%) was much higher in this protocol than that seen in the trial by de Vos et al, and was significantly associated with achieving a complete response or partial response. Neurotoxicity limited the tolerability of this regimen, and the authors recommended that future studies examine once-weekly bortezomib-rituximab combinations. Similar to other rituximab-bortezomib combination trials, the study by Baiocchi et al concluded that a large randomized trial would be needed to delineate better whether the efficacy seen with bortezomib in patients with relapsed or even rituximab-refractory follicular lymphoma could outweigh the added toxicities which resulted from the combination regimen.

In August 2011, the anticipated results of such a trial using the better tolerated weekly regimen of bortezomib were published. Coiffier et al, on behalf of the LYM-3001study investigators, reported the results of a randomized, multinational (164 centers in 29 countries) Phase III clinical trial which included 676 patients with relapsed or refractory follicular lymphoma. Patients were randomized to receive rituximab $375 \mathrm{mg} / \mathrm{m}^{2}$ on days $1,8,15$, and 22 of a 35-day cycle for cycle 1 , and on day 1 only for cycles $2-5$, either alone or with bortezomib given weekly at $1.6 \mathrm{mg} / \mathrm{m}^{2}$ on days $1,8,15$, and 22 of all cycles. Five cycles were planned. The primary endpoint was progression-free survival and, at the end of a median 33.9 months of follow-up, a significant increase in progression-free survival was seen in the bortezomib plus rituximab arm (12.8 months) compared with the rituximab only treatment arm (11 months). This also coincided with a better overall response rate in the combination arm versus the rituximab only arm (63\% versus $49 \%$, respectively). ${ }^{42}$ However, the safety profiles revealed higher rates of grade 3 or higher adverse events, serious adverse events, and adverse events leading to withdrawal from the study in the patients treated with bortezomib plus rituximab; and although the progression-free survival difference was statistically longer in the bortezomib plus rituximab arm, it was a small absolute difference (less than 2 months) and was less than the $33 \%$ expected difference prespecified at study design. The authors proposed that the combination regimen of bortezomib plus rituximab may benefit certain subpopulations with adverse prognostic factors, but the results of bortezomib in combination with rituximab were not as impressive as hoped for, and again attention refocused on ongoing trials which explored the potential of bortezomib combined with other established chemoimmunotherapy regimens.

\section{Combination chemoimmunotherapy trials}

Preclinical and early Phase I and II trials of single-agent bortezomib suggested that chemoresistant malignant cells responded to proteasome inhibition, and that there could be a synergistic effect from the combination of proteasome inhibitors with the cytotoxic effects of other chemotherapeutic and immunotherapeutic regimens. ${ }^{43-49}$ The complementary mechanisms of action of proteasome inhibitors with conventional cytotoxic therapy can occur on several levels, including lowering the apoptotic threshold 
of the cell by overcoming molecular mechanisms of drug resistance (ie, overexpression of NF- $\mathrm{KB}$ induced by chemotherapies), downregulation of constitutively active signaling proteins involved in proliferation pathways (ie, phosphorylated-Akt in the PI3k/akt pathway), and inhibiting DNA repair enzymes so that the DNA damaging action of anthracyclines or other agents have greater effect. ${ }^{14,37,50,51}$

Several Phase II studies have been published regarding the combination of bortezomib with other chemoimmunotherapies in non-Hodgkin's lymphoma, including follicular lymphoma, and selected studies are summarized in Table 3 (regimens containing rituximab plus cyclophosphamide, doxorubicin, vincristine, and prednisone [R-CHOP] and rituximab, cyclophosphamide, vincristine, and prednisone [R-CVP]) and Table 4 (regimens containing rituximabbendamustine.) In 2009, GELA reported on a randomized Phase II trial of the addition of biweekly versus weekly bortezomib to R-CHOP as initial treatment in CD20+ $\mathrm{B}$ cell lymphomas. Based on good tolerability, the dose of bortezomib was increased in the last 25 patients enrolled from $1 \mathrm{mg} / \mathrm{m}^{2}$ to $1.3 \mathrm{mg} / \mathrm{m}^{2}$ in the biweekly dosing and from $1.3 \mathrm{mg} / \mathrm{m}^{2}$ to $1.6 \mathrm{mg} / \mathrm{m}^{2}$ in the weekly dosing arm. Eleven patients with follicular lymphoma were enrolled and the complete response/unconfirmed complete response rate in follicular lymphoma for the combined arm was $82 \%$. The response rate in all subjects appeared higher in the biweekly arm (complete response/unconfirmed complete response of $90 \%$ versus $79 \%$ ), though the study was not designed to determine if these differences were statistically different. The neurologic toxicities with bortezomib also appeared higher in the biweekly bortezomib group and with the higher doses of bortezomib. Grade 3 neurologic toxicity occurred in $70 \%$ of patients receiving biweekly $1.3 \mathrm{mg} / \mathrm{m}^{2}$ bortezomib versus $0 \%$ at the lower dose $\left(1 \mathrm{mg} / \mathrm{m}^{2}\right)$, and in $27 \%$ of patients receiving weekly $1.6 \mathrm{mg} / \mathrm{m}^{2}$ bortezomib versus $7 \%$ at weekly $1.3 \mathrm{mg} / \mathrm{m}^{2}$. The investigators concluded, in line with other available evidence, that dosing of biweekly bortezomib in combination with R-CHOP should not exceed doses of $1 \mathrm{mg} / \mathrm{m}^{2} .^{52,53}$ Whether lower doses add meaningful benefit, especially given the significant side effects that still occur at these doses, is questionable and likely part of the

Table 3 Clinical trials of R-CVP/R-CHOP with and without bortezomib

\begin{tabular}{|c|c|c|c|c|}
\hline \multirow[t]{2}{*}{ Population } & \multirow{2}{*}{$\begin{array}{l}\text { Bortezomib dosing } \\
\text { schedule }\end{array}$} & \multirow{2}{*}{$\begin{array}{l}\text { Response rates } \\
\text { for all patients }\end{array}$} & \multicolumn{2}{|c|}{ Toxicities reported as percentage of patients } \\
\hline & & & Neuropathy & Gr $3 / 4$ heme toxicity \\
\hline $\begin{array}{l}\text { Previously untreated patients } \\
\text { with CD20-positive } \\
\text { B cell lymphomas } \\
n=49(22 \% \mathrm{FL})\end{array}$ & $\begin{array}{l}\text { Arm A: biweekly bortezomib } \\
\left(\mathrm{I} .0-\mathrm{I} .3 \mathrm{mg} / \mathrm{m}^{2}\right)+\mathrm{R}-\mathrm{CHOP} \\
\text { (six cycles) } \mathrm{n}=20\end{array}$ & CR/CRu: $90 \%(18 / 20)$ & $\begin{array}{l}25 \% \text { overall; } 71 \% \\
\text { at } 1.3 \mathrm{mg} / \mathrm{m}^{2} \text { dose }\end{array}$ & $\begin{array}{l}\text { Leukopenia: } \\
35 \% \text { of cycles } \\
\text { thrombocytopenia: } \\
35 \% \text { of cycles }\end{array}$ \\
\hline Ribrag et $a^{52}$ & $\begin{array}{l}\text { Arm B: weekly bortezomib } \\
\left(\mathrm{I} .3-\mathrm{I} .6 \mathrm{mg} / \mathrm{m}^{2}\right)+\mathrm{R}-\mathrm{CHOP} \\
\text { (six cycles), } \mathrm{n}=29\end{array}$ & CR/CRu: 79\% (23/29) & $\begin{array}{l}17 \% \text { overall; } 27 \% \\
\text { at } 1.6 \mathrm{mg} / \mathrm{m}^{2} \text { dose }\end{array}$ & $\begin{array}{l}\text { Leukopenia: } 44 \% \\
\text { of cycles } \\
\text { Thrombocytopenia: } 0 \%\end{array}$ \\
\hline $\begin{array}{l}\text { Previously untreated patients } \\
\text { with low-grade B cell NHL } \\
n=5 \text { I } 3 \text { total } \\
(54 \% \mathrm{FL}) \mathrm{n}=253 \\
\text { for R-CHOP } \\
(55 \% \mathrm{FL}) \\
\text { Rummel et } \mathrm{al}^{70}\end{array}$ & $\begin{array}{l}\text { R-CHOP versus } \\
\text { R-bendamustine } \\
\text { (data presented here } \\
\text { for the R-CHOP arm only) }\end{array}$ & $\begin{array}{l}\text { CR } 30 \% \text {; Median PFS } \\
35 \text { months }\end{array}$ & Paresthesias: $29 \%$ & $\begin{array}{l}\text { Neutropenia: } \\
46 \% \text { of cycles }\end{array}$ \\
\hline $\begin{array}{l}\text { Low-grade B cell NHL } \\
\mathrm{n}=40(\% \text { w/FL NR) } \\
\text { Czuczman et al }{ }^{69}\end{array}$ & R-CHOP (six cycles) & $\begin{array}{l}\text { ORR: } 95 \% \\
\text { CR: } 55 \%\end{array}$ & $\begin{array}{l}\text { Paresthesias: } 12.5 \% \\
\text { (all grade I) }\end{array}$ & $\begin{array}{l}\text { Neutropenia: } 60 \% \\
\text { Thrombocytopenia: } 10 \%\end{array}$ \\
\hline $\begin{array}{l}\text { Previously untreated patients } \\
\text { with FL } n=94(100 \% \mathrm{FL}) \\
\text { Sehn et } \mathrm{a}^{54}\end{array}$ & $\begin{array}{l}\text { Weekly bortezomib } \\
\left(1.3 \mathrm{mg} / \mathrm{m}^{2}\right)+\mathrm{R}-\mathrm{CVP}\end{array}$ & $\begin{array}{l}\text { ORR: } 83 \% \\
\text { CR/CRu: } 49 \%\end{array}$ & $\begin{array}{l}\text { Sensory } 75 \% \text { ( } 5 \% \text { Grade } 3 / 4) \text {; } \\
\text { Motor } 9 \%(0 \% \text { grade } 3 / 4) \text {; } \\
\text { neuropathic pain } 29 \% \\
\text { (1\% grade } 3 / 4)\end{array}$ & $\begin{array}{l}\text { Neutropenia: } 28 \% \\
\text { Thrombocytopenia: } 3 \%\end{array}$ \\
\hline $\begin{array}{l}\text { Previously untreated patients } \\
\text { with stages III/IV FL } n=321 \\
\text { total (I00\% FL) } n=162 \\
\text { for R-CVP arm } \\
\text { Marcus et al }{ }^{55}\end{array}$ & $\begin{array}{l}\text { R-CVP versus CVP (8 cycles) } \\
\text { (data presented here for the } \\
\text { R-CVP arm only) }\end{array}$ & $\begin{array}{l}\text { ORR: } 81 \% \text { CR/CRu: } \\
\text { 4I\% median TTP: } 35 \text { mo }\end{array}$ & NR & Neutropenia: $24 \%$ \\
\hline
\end{tabular}

Abbreviations: FL, follicular lymphoma; ORR, overall response rate; NR, not reported; AE, adverse events; CR/CRu, complete response/complete response unconfirmed; $\mathrm{NHL}$, non-Hodgkin's lymphoma; PFS, progression-free survival; R-CHOP, rituximab, cyclophosphamide, vincristine, prednisone, doxorubicin; R-CVP, rituximab, cyclophosphamide, vincristine, prednisone; TTP, time to progression. 
Table 4 Clinical trials of bendamustine with or without bortezomib

\begin{tabular}{|c|c|c|c|c|}
\hline \multirow[t]{2}{*}{ Population } & \multirow{2}{*}{$\begin{array}{l}\text { Bortezomib dosing } \\
\text { schedule }\end{array}$} & \multirow{2}{*}{$\begin{array}{l}\text { Response rates } \\
\text { for FL patients } \\
\text { unless otherwise stated }\end{array}$} & \multicolumn{2}{|c|}{ Toxicities reported as percentage of patients } \\
\hline & & & Neuropathy & Gr 3/4 hematologic toxicity \\
\hline $\begin{array}{l}\text { Relapsed/refractory } \\
\text { indolent B cell NHL } \\
n=31 \text { ( } 52 \% \mathrm{FL}) \\
\text { Freidberg et a }\left.\right|^{59}\end{array}$ & $\begin{array}{l}\text { Weekly bortezomib } \\
\left(1.3 \mathrm{mg} / \mathrm{m}^{2}\right)+\text { rituximab- } \\
\text { bendamustine }\left(90 \mathrm{mg} / \mathrm{m}^{2}\right)\end{array}$ & $\begin{array}{l}\text { ORR 93\%; } 2 \text { year PFS } \\
\text { for all patients } 47 \%\end{array}$ & $\begin{array}{l}\text { Peripheral } \\
\text { neuropathy: } 47 \% \\
\text { (7\% Gr 3; } 0 \% \text { Gr 4) }\end{array}$ & $\begin{array}{l}\text { Neutropenia: I7\% } \\
\text { Thrombocytopenia: I7\% }\end{array}$ \\
\hline $\begin{array}{l}\text { Relapsed/refractory } \\
\text { patients with FL } \\
\text { with prior rituximab } \\
\text { exposure } \mathrm{n}=73 \text { ( } 100 \% \mathrm{FL}) \\
\text { Fowler et al, } \\
\text { the VERTICAL study }{ }^{58}\end{array}$ & $\begin{array}{l}\text { Biweekly bortezomib } \\
\left(1.6 \mathrm{mg} / \mathrm{m}^{2}\right)+ \\
\text { R-bendamustine } \\
\left(50-90 \mathrm{mg} / \mathrm{m}^{2}\right)\end{array}$ & $\begin{array}{l}\text { ORR } 88 \% \\
\text { CR } 53 \% \\
\text { CR median } \\
\text { PFS } 14.9 \text { months }\end{array}$ & $\begin{array}{l}\text { Peripheral } \\
\text { neuropathy: } 44 \% \\
\text { (II\% grade } 3, \\
0 \% \text { grade } 4)\end{array}$ & $\begin{array}{l}\text { Neutropenia: } 25 \% \\
\text { Thrombocytopenia: } 14 \%\end{array}$ \\
\hline $\begin{array}{l}\text { Previously untreated } \\
\text { low-grade B cell } \mathrm{NHL} \\
\mathrm{n}=5 \mathrm{I} 3 \text { total }(54 \% \mathrm{FL}) \\
\mathrm{n}=260 \text { for bendamustine } \\
\text { arm }(53 \% \mathrm{FL}) \\
\text { Rummel et al }{ }^{70}\end{array}$ & $\begin{array}{l}\text { R-bendamustine } \\
\left(90 \mathrm{mg} / \mathrm{m}^{2}\right) \text { versus } \\
\text { RCHOP (data } \\
\text { presented here for the } \\
\text { bendamustine arm only) }\end{array}$ & CR $40 \%$ in all patients & Paresthesias: $7 \%$ & Neutropenia: II\% \\
\hline $\begin{array}{l}\text { Relapsed/refractory MCL } \\
\text { or low-grade B cell NHL } \\
n=63(38 \% \mathrm{FL}) \\
\text { Rummel et al }{ }^{56}\end{array}$ & $\begin{array}{l}\text { Rituximab- } \\
\text { bendamustine } \\
\left(90 \mathrm{mg} / \mathrm{m}^{2}\right)\end{array}$ & $\begin{array}{l}\text { ORR } 96 \% \text { all patients } \\
\text { CR } 71 \%\end{array}$ & $0 \%$ & $\begin{array}{l}\text { Leukopenia: } 16 \% \text { of cycles } \\
\text { Thrombocytopenia: } \\
3 \% \text { of cycles }\end{array}$ \\
\hline $\begin{array}{l}\text { Relapsed/refractory } \\
\text { indolent } \mathrm{B} \text { cell } \mathrm{NHL} \\
\text { not-rituximab-refractory } \\
\mathrm{n}=66(61 \% \mathrm{FL}) \\
\text { Robinson et al }{ }^{57}\end{array}$ & $\begin{array}{l}\text { Rituximab- } \\
\text { bendamustine } \\
\left(90 \mathrm{mg} / \mathrm{m}^{2}\right)\end{array}$ & $\begin{array}{l}\text { ORR } 93 \% \text { for all patients; } \\
54 \% \text { CR/CRu }\end{array}$ & NR & $\begin{array}{l}\text { Neutropenia: } 36 \% \\
\text { Thrombocytopenia: } 9 \%\end{array}$ \\
\hline
\end{tabular}

reason this chemotherapy combination has not gained use in follicular lymphoma.

In keeping with the search for both synergistic and safe bortezomib-containing combination therapies, the National Cancer Institute of Canada Clinical Trials Group completed a study of bortezomib and R-CVP in patients with newly diagnosed follicular lymphoma requiring treatment. Recognizing the morbidities which can be associated with bortezomibinduced neurotoxicities, and the risk of heightened toxicity when combined with a vinca alkaloid, the investigators chose a lower bortezomib dose $\left(1.3 \mathrm{mg} / \mathrm{m}^{2}\right)$ and a weekly schedule (day 1 and 8). ${ }^{54}$ They also planned a detailed analysis of neurotoxicities, with the incidence of significant peripheral neuropathy as a primary endpoint. The complete response rate was also a primary endpoint, with a hypothesis that the complete response/unconfirmed complete response would be at least $56 \%$, a number that was extrapolated from the results of the primary R-CVP study for patients with relapsed follicular lymphoma in whom complete response/ unconfirmed complete response rates were $41 \% .{ }^{55}$ For the 94 patients enrolled in this bortezomib plus R-CVP trial, the regimen was very well tolerated and $90 \%$ of patients completed the planned eight cycles of treatment. There were no grade 4 neurotoxicities and only $5 \%$ had grade 3 neurologic complications. However, despite this favorable side effect profile and overall response rate of $83 \%$, the $49 \%$ complete response did not meet the primary endpoint predicted to show improvement of complete response/unconfirmed complete response to $56 \%$.

Bendamustine has recently been approved for use in relapsed/refractory follicular lymphoma. In combination with rituximab, it is a highly effective regimen, with greater than $90 \%$ overall response rates in relapsed indolent and mantle cell lymphomas. ${ }^{56,57}$ Unlike the RCHOP/RCVP regimens, this agent is not associated with neurologic side effects, so bortezomib plus bendamustine may increase the efficacy of both agents without limitations from overlapping neurotoxicities.

Two Phase II trials of the combination of bortezomib, bendamustine, and rituximab have been completed. In the larger VERTICAL study (VELCADE in Relapsed or Refractory Follicular Lymphoma) published by Fowler et al 
in 2011, 73 patients with relapsed or refractory follicular lymphoma were enrolled to receive five 35-day cycles of weekly bortezomib, bendamustine, and rituximab $\left(375 \mathrm{mg} / \mathrm{m}^{2}\right)$. Bortezomib was administered intravenously at a dose of $1.6 \mathrm{mg} / \mathrm{m}^{2}$ on days $1,8,15$, and 22 . This was a Phase I/II trial with dose escalation of bendamustine from $50 \mathrm{mg} / \mathrm{m}^{2}$ to $90 \mathrm{mg} / \mathrm{m}^{2}$. All doses were well tolerated, so the $90 \mathrm{mg} / \mathrm{m}^{2}$ dose on days 1 and 2 was used in the Phase II expansion study. In the 60 evaluable patients treated at the $90 \mathrm{mg} / \mathrm{m}^{2}$ dose level of bendamustine, the overall response rate was $88 \%$ (53\% complete response) and median progression-free survival was 14.9 months. ${ }^{58}$ Considering that $47 \%$ of the patients did not respond to their last treatment and 44\% were refractory to rituximab, response rates were especially encouraging at $89 \%$ and $95 \%$ in these groups, respectively. Based on complete response/unconfirmed complete response rates of $56 \%-60 \%$ in trials of bendamustine-rituximab in relapsed/refractory indolent non-Hodgkin's lymphoma, ${ }^{56,57}$ the authors had hypothesized that the complete response rate with the addition of bortezomib would be over $60 \%$. Though the study did not reject the null hypothesis because the complete response rate was $<60 \%$, such a large improvement in complete response may have been an ambitious goal, given the heavily pretreated nature of this population.

Although most patients were able to receive the planned number of cycles (median five cycles) in the VERTICAL study, toxicity was high. Sixty-six percent of the 73 patients included in the safety analysis experienced grade 3 or greater adverse events felt to be drug-related (majority from myelosuppression), $30 \%$ had dose reductions in therapy, and $22 \%(n=16)$ discontinued therapy due to adverse events. In addition, 12 patients experienced reactivation of herpes zoster which prompted investigators to recommend prophylaxis for future bortezomib plus bendamustine-rituximab regimens, although half of the patients with outbreaks were already on antiviral prophylactic medications.

In the other multicenter trial evaluating bendamustinerituximab combined with bortezomib, investigators chose a biweekly bortezomib dosing schedule, based on evidence of better efficacy with this regimen in the single-agent setting. It was a smaller study of 31 patients with relapsed or refractory indolent lymphoma and mantle cell lymphoma, and only 16 patients with follicular lymphoma were included. Patients were scheduled to receive six 28-day cycles of bendamustine $90 \mathrm{mg} / \mathrm{m}^{2}$ on days 1 and 4 and rituximab $375 \mathrm{mg} / \mathrm{m}^{2}$ on day 1 combined with bortezomib on days $1,4,8$, and $11 .{ }^{59}$ Most of the grade 3 or 4 toxicities were hematologic, with five patients $(17 \%)$ each developing grade 3 or higher thrombocytopenia and neutropenia. Fourteen patients (47\%) developed peripheral neuropathy, but it was only grade 3 or higher in two patients and most symptoms resolved after cessation of treatment. Reactivation of herpes zoster infection was also seen, occurring in four patients $(13 \%$, no patients were on antiviral prophylaxis). The overall response rate was as encouraging as the VERTICAL study, with 93\% partial response and complete response rates observed for follicular lymphoma, and an $83 \%$ overall response rate for all included patients. However, the 2-year progression-free survival for all treated patients was $47 \%$, which did not meet the primary endpoint of $25 \%$ improvement as compared with the historical use of bendamustine-rituximab.

Although neither of these trials demonstrated an improvement in response rate or progression-free survival with the addition of bortezomib to bendamustine-rituximab, crosstrial comparisons are difficult to make because of differences in trial design. The patients enrolled in the bortezomibbendamustine-rituximab trials had more refractory disease and were more heavily pretreated than in the bendamustinerituximab studies (Table 4 ). Therefore, by achieving results equivalent to those of the bendamustine-rituximab studies, one could argue that bortezomib did improve outcomes just as easily as concluding that it had little additional benefit. In addition, positron emission tomography was not used to assess response in the bendamustine-rituximab studies, so some responses graded as a complete response might have been counted as a partial response if positron emission tomography scans had been performed.

The added toxicity from combining bortezomib with bendamustine-rituximab is not insignificant, with nearly a quarter of patients dropping out of both bortezomib trials because of adverse events and $26 \%-34 \%$ of patients experiencing a serious adverse event. In contrast, patient withdrawal due to adverse events was extremely uncommon in the bendamustine-rituximab studies, at less than $3 \%$. In the end, without a randomized controlled trial comparing bendamustine-rituximab \pm bortezomib, no definite conclusions can be drawn about the benefits of adding bortezomib and whether they outweigh the additional risks.

\section{Toxicity including neuropathy}

Any treatment decision, particularly in relapsed disease where patients have likely already accumulated symptoms from previous treatments or the lymphoma itself, must balance perceived therapeutic benefit with treatment-related morbidity and mortality. Though bortezomib is often considered safe and well tolerated across patient groups, 
including in the elderly, ${ }^{60}$ the potential for significant toxicities in single-agent or combination regimens should be considered. Tables 1-4 include all reported neurotoxicities, and grade 3 or 4 non-neurologic toxicities, as reported in the trials involving bortezomib in follicular lymphoma.

Classically bortezomib has been associated with peripheral sensory neuropathy, with or without accompanying painful or burning dysesthesias. This occurred in up to $74 \%$ of patients included in the follicular lymphoma studies reviewed herein, varying greatly depending upon the bortezomib dose, schedule (weekly or biweekly), or if used in combination with other chemoimmunotherapies. In addition to sensory neuropathy, bortezomib can also be associated with a motor neuropathy leading to lower extremity weakness, or an autonomic neuropathy manifesting as orthostatic hypotension or gastrointestinal side effects, such as constipation. For example, when the Baiocchi et al rituximab-bortezomib study assessed for sensory, motor, and autonomic neuropathy (orthostatic hypotension, constipation/ ileus) they increased their appraisal of grade 3 neuropathy to $54 \%$ from $40 \%$ when only considering peripheral neuropathy. ${ }^{41}$ However, many other single-agent or combination studies did not include assessment beyond sensory neuropathy or neuropathic pain.

Also complicating the assessment of bortezomib-induced neuropathy is the frequency of baseline peripheral neuropathy for study participants, many of whom had previously been exposed to neurotoxic medications, such as vincristine. Baseline neuropathy was not well described in all studies, though some studies question whether prior vincristine truly predicts the development of grade 3/4 neuropathy. ${ }^{41}$ The complexities of clinical or biological factors that increase the risk for development of neuropathy while on bortezomib-based therapy are not well appreciated from available evidence.

The exact mechanism for bortezomib-induced neuropathy is uncertain, though animal based studies have demonstrated direct mitochondrial damage in Schwann cells of the sciatic nerve and in the dorsal root ganglia. This damage occurs to a greater intensity in more distal cells, which correlates with the distribution of neuropathic symptoms in the fingers and toes in patients. ${ }^{61}$ It has been suggested that this damage from bortezomib occurs upon surpassing a certain threshold dose, not from cumulative toxicity, ${ }^{62}$ and frequently in the studies of non-Hodgkin's lymphoma and multiple myeloma investigators reported reversal of symptoms after the medication was held. ${ }^{42,54,58,63}$ Many would argue that the best treatment for bortezomib-induced neuropathy is prevention and avoiding its use in high-risk patients. Unfortunately, to date, no patient subgroup has been definitively linked to development of grade 3 or 4 peripheral neuropathy.

From the success and widespread use of bortezomib in multiple myeloma, criteria for dose modifications of bortezomib when neuropathy or other toxicities occur have been developed. ${ }^{64}$ These modifications allow for continued therapeutic drug dosing while minimizing or reversing symptoms. Quality of life assessments will aid in answering whether the potential benefit from new bortezomib-containing regimens outweighs the increased rates of neuropathy, a critical determination in an indolent disease such as follicular lymphoma where the goal of therapy is generally palliative.

\section{Conclusion and future directions}

In conclusion, despite preclinical data and the encouraging results of bortezomib in other hematologic malignancies, with multiple myeloma shining as the hallmark of its success, treatment with bortezomib in follicular lymphoma has resulted in diverse response rates as a single agent (overall response rate $16 \%-41 \%)^{65}$ and provided questionable added benefit compared with established regimens such as rituximab, R-CHOP, bendamustine-rituximab, or R-CVP. In fact, most of the bortezomib combination trials did not meet their primary endpoint because of the failure of bortezomib to improve responses or survival to the degree anticipated. Though various alterations in the bortezomib dosing schedule (ie, biweekly) may result in increased response rates, this was not always true when it was used in combination with other drugs, and biweekly or combination treatment was often also associated with an increase in drug-related neurotoxicity. Such toxicities are especially limiting in a disease such as follicular lymphoma where overall survival is measured in years but cure is rarely obtained. Therefore, new therapies must not only show tumor response but also justify the toxicities of therapy, either by ameliorating disease-related symptoms refractory to other effective treatment, prolonging time until further therapy is needed, or by increasing overall survival. With the current evidence, it is difficult to conclude that bortezomib for the treatment of follicular lymphoma satisfies these conditions.

The reason for the conflicting and somewhat disappointing results in follicular lymphoma could be multifactorial, from the incorrect extrapolation of in vitro data for the mechanism of action of bortezomib in mantle cell lymphoma or diffuse large B cell lymphoma cell lines to its potential in follicular lymphoma, the oversimplification of pathways involved in follicular lymphoma pathobiology, the inability of patients to receive full effective treatment doses 
because of toxicities, or limitations in study design. With this recognition, there perhaps still remains potential for bortezomib in the treatment of follicular lymphoma. Better randomized trials are planned, such as bortezomib plus R-CVP versus R-CVP, and bendamustine-rituximab with or without bortezomib, ${ }^{54,59}$ to eliminate patient disparities and other confounding variables discussed in the trials earlier, as well as to investigate possible subgroups of patients with follicular lymphoma more likely to respond to bortezomibcontaining regimens. In addition, recent evidence has demonstrated reduced toxicities of bortezomib when given as an injection ${ }^{66}$ and this may enable patients to complete intended therapy with fewer side effects. Other potential toxicities may arise if bortezomib is combined with alternative treatment modalities, such as radioimmunotherapy ${ }^{67}$ or with important intracellular targets for follicular lymphoma currently in development, such as NF- $\kappa \mathrm{B}$ inhibitors, histone deacetylase inhibitors, heat-shock protein 90 inhibitors, or pan-Bcl-2 family inhibitors. ${ }^{68}$ These novel treatment combinations may target important intracellular signaling at more than one level for better efficacy, and most importantly may reduce treatment-related morbidity and mortality by lowering the required dose of bortezomib, and by providing an alternative treatment regimen to the systemic toxicities of conventional chemotherapy.

Continued discoveries, such as those discussed above, are anticipated to bring promising new targeted treatments for follicular lymphoma, and additional evidence on the optimal way to utilize these drugs to affect meaningful patient outcomes. The degree to which bortezomib will be involved in these future developments to improve follicular lymphoma care is yet to be determined.

\section{Disclosure}

AWB has received research support from Millennium.

\section{References}

1. Friedberg JW, Taylor MD, Cerhan JR, et al. Follicular lymphoma in the United States: First Report of the National LymphoCare Study. J Clin Oncol. 2009;27:1202-1208.

2. Jemal A, Siegel R, Xu J, Ward E. Cancer statistics. CA Cancer J Clin. 2010;60:277-300.

3. Damaj G, Verkarre V, Delmer A, et al. Primary follicular lymphoma of the gastrointestinal tract: a study of 25 cases and a literature review. Ann Oncol. 2003;14:623-629.

4. Goodlad JR, MacPherson S, Jackson R, Batstone P, White J. Extranodal follicular lymphoma: a clinicopathological and genetic analysis of 15 cases arising at non-cutaneous extranodal sites. Histopathology. 2004; 44:268-276.

5. Fernandez de Larrea C, Martinez-Pozo A, Mercadal S, et al. Initial features and outcome of cutaneous and non-cutaneous primary extranodal follicular lymphoma. Br J Haematol. 2011;153:334-340.
6. Pugh TJ, Ballonoff A, Newman F, Rabinovitch R. Improved survival in patients with early stage low-grade follicular lymphoma treated with radiation: a surveillance, epidemiology, and end results database analysis. Cancer. 2010;116:3843-3851.

7. MacManus MP, Hoppe RT. Is radiotherapy curative for stage I and II low-grade follicular lymphoma? Results of a long-term follow-up study of patients treated at Stanford University. J Clin Oncol. 1996;14:1282-1290.

8. Wilder RB, et al. Long-term results with radiotherapy for stage I-II. follicular lymphomas. Int J Radiat Oncol Biol Phys. 2001;51:1219-1227.

9. Brice P, Bastin Y, Lepage E, et al. Comparison in low-tumor-burden follicular lymphomas between an initial no-treatment policy, prednimustine, or interferon alfa: a randomized study from the Groupe D'Etude des Lymphomes Folliculaires. J Clin Oncol. 1997;15:1110-1117.

10. Advani R, Rosenberg SA, Horning SJ. Stage I and II follicular nonHodgkin's lymphoma: long-term follow-up of no initial therapy. J Clin Oncol. 2004;22:1454-1459.

11. Ardeshna KM, Norton A, Hoskin PJ, et al. Long-term effect of a watch and wait policy versus immediate systemic treatment for asymptomatic advanced-stage non-Hodgkin lymphoma: a randomised controlled trial. Lancet. 2003;362:516-522.

12. Morton LM, Wang SS, Devesa SS, Hartge P, Welsenburger DD, Linet MS. Lymphoma incidence patterns by WHO subtype in the United States, 1992-2001. Blood. 2006;107:265-276.

13. Fisher RI, LeBlanc M, Press OW, Maloney DG, Unger JM, Miller TP. New treatment options have changed the survival of patients with follicular lymphoma. J Clin Oncol. 2005;23:8447-8452.

14. Orlowski RZ. The ubiquitin proteasome pathway from bench to bedside. Hematology Am Soc Hematol Educ Program. 2005:220-225.

15. Adams J. The proteasome: a suitable antineoplastic target. Nat Rev Cancer. 2004;4:349-360.

16. Voorhees PM, Dees EC, O'Neil B, et al. The proteasome as a target for cancer therapy. Clin Cancer Res. 2003;9:6316-6325.

17. Adams J, Palombella VJ, Sausville EA, et al. Proteasome inhibitors: a novel class of potent and effective antitumor agents. Cancer Res. 1999;59:2615-2622.

18. Hideshima T, Richardson $\mathrm{P}$, Chauhan D, et al. The proteasome inhibitor PS-341 inhibits growth, induces apoptosis, and overcomes drug resistance in human multiple myeloma cells. Cancer Res. 2001;61:3071-3076.

19. Orlowski RZ, Eswara JR, Lafond-Walker A, et al. Tumor growth inhibition induced in a murine model of human Burkitt's lymphoma by a proteasome inhibitor. Cancer Res. 1998;58:4342-4348.

20. Bagg A. B cells behaving badly: a better basis to behold belligerence in B-cell lymphomas. Hematology Am Soc Hematol Educ Program. 2011;2011:330-335.

21. Cory S, Huang DC, Adams JM. The Bcl-2 family: roles in cell survival and oncogenesis. Oncogene. 2003;22:8590-8607.

22. Ling Y, Liebes L, Ng B, et al. PS-341, a novel proteasome inhibitor, induces Bcl-2 phosphorylation and cleavage in association with G 2-M phase arrest and apoptosis. Mol Cancer Ther. 2002;1:841-849.

23. An B, Goldfarb RH, Siman R, Dou QP. Novel dipeptidyl proteasome inhibitors overcome Bcl-2 protective function and selectively accumulate the cyclin-dependent kinase inhibitor p27 and induce apoptosis in transformed, but not normal, human fibroblasts. Cell Death Differ. 1998;5:1062-1075.

24. Turco MC, Romano MF, Petrella A, Bisogni R, Tassone P, Venuta S. $\mathrm{NF}-\mathrm{\kappa B} /$ Rel-mediated regulation of apoptosis in hematologic malignancies and normal hematopoietic progenitors. Leukemia. 2004;18:11-17.

25. Strauss SJ, Higginbottom K, Juliger S, et al. The proteasome inhibitor bortezomib acts independently of p53 and induces cell death via apoptosis and mitotic catastrophe in B-cell lymphoma cell lines. Cancer Res. 2007;67:2783-2790.

26. Pham LV, Tamayo AT, Yoshimura LC, Lo P, Ford RJ. Inhibition of constitutive NF- $\kappa$ B activation in mantle cell lymphoma B cells leads to induction of cell cycle arrest and apoptosis J Immunol. 2003;171:88-95. 
27. Fisher RI, Berstein SH, Kahl BS, et al. Multicenter Phase II study of bortezomib in patients with relapsed or refractory mantle cell lymphoma. J Clin Oncol. 2006;24:4867-4874.

28. Goy A, Younes A, McLaughlin P, et al. Phase II study of proteasome inhibitor bortezomib in relapsed or refractory B-cell non-Hodgkin's lymphoma. J Clin Oncol. 2005;23:667-675.

29. O'Connor OA, Wright J, Moskowitz C, et al. Phase II Clinical experience with the novel proteasome inhibitor bortezomib in patients with indolent non-Hodgkin's lymphoma and mantle cell lymphoma. J Clin Oncol. 2005;23:676-684.

30. Strauss SJ, Maharaj L, Hoare S, et al. Bortezomib therapy in patients with relapsed or refractory lymphoma: potential correlation of in vitro sensitivity and tumor necrosis factor alpha response with clinical activity. J Clin Oncol. 2006;24:2105-2112.

31. Di Bella N, Taetle R, Kolibaba K, et al. Results of a Phase 2 study of bortezomib in patients with relapsed or refractory indolent lymphoma. Blood. 2010;115:475-480.

32. O'Connor OA, Portlock C, Moskowitz C, et al. Time to treatment response in patients with follicular lymphoma treated with bortezomib is longer compared with other histologic subtypes. Clin Cancer Res. 2010;16:719-726.

33. Gerecitano J, Portlock C, Moskowitz C, et al. Phase 2 study of weekly bortezomib in mantle cell and follicular lymphoma. $\mathrm{Br} J$ Haematol. 2009;146:652-655.

34. Ribrag V, Tilly H, Casasnovas O, et al. Final results of a randomized Phase 2 multicenter study of two bortezomib schedules in patients with recurrent or refractory follicular lymphoma: Groupe d'Etude des Lymphomes de l'Adulte (GELA) Study FL-05. Blood. 2010; 116:Abstr 768.

35. Smolewski P, Duechler M, Linke A, et al. Additive cytotoxic effect of bortezomib in combination with anti-CD20 or anti-CD52 monoclonal antibodies on chronic lymphocytic leukemia cells. Leuk Res. 2006;30:1521-1529.

36. de Vos S, Goy A, Dakhil SR, et al. Multicenter randomized Phase II study of weekly or twice-weekly bortezomib plus rituximab in patients with relapsed or refractory follicular or marginal-zone B-cell lymphoma. J Clin Oncol. 2009;27:5023-5030.

37. Alinari L, White VL, Earl CT, et al. Combination bortezomib and rituximab treatment affects multiple survival and death pathways to promote apoptosis in mantle cell lymphoma. MAbs. 2009;1:31-40.

38. Czuczman MS, Olejniczak S, Gowda A, et al. Acquirement of rituximab resistance in lymphoma cell lines is associated with both global CD20 gene and protein down-regulation regulated at the pretranscriptional and posttranscriptional levels. Clin Cancer Res. 2008;14:1561-1570.

39. Agathocleous A, Rohatiner A, Rule S, et al. Weekly versus twice weekly bortezomib given in conjunction with rituximab, in patients with recurrent follicular lymphoma, mantle cell lymphoma and Waldenstrom macroglobulinaemia. Br J Haematol. 2010;151:346-353.

40. Richardson PG, Xie W, Mitsiades C, et al. Single-agent bortezomib in previously untreated multiple myeloma: efficacy, characterization of peripheral neuropathy, and molecular correlations with response and neuropathy. J Clin Oncol. 2009;27:3518-3525.

41. Baiocchi RA, Alinari L, Lustberg ME, et al. Phase 2 trial of rituximab and bortezomib in patients with relapsed or refractory mantle cell and follicular lymphoma. Cancer. 2011;117:2442-2451.

42. Coiffier B, Osmanov EA, Hong X, et al. Bortezomib plus rituximab versus rituximab alone in patients with relapsed, rituximab-naive or rituximab-sensitive, follicular lymphoma: a randomised Phase 3 trial. Lancet Oncol. 2011;12:773-784.

43. Mortenson MM, Schlieman MG, Virudachalam S, Bold RJ. Effects of the proteasome inhibitor bortezomib alone and in combination with chemotherapy in the A549 non-small-cell lung cancer cell line. Cancer Chemother Pharmacol. 2004;54:343-353.

44. Duechler M, Linke A, Cebula B, et al. In vitro cytotoxic effect of proteasome inhibitor bortezomib in combination with purine nucleoside analogues on chronic lymphocytic leukaemia cells. Eur J Haematol. $2005 ; 74: 407-417$.
45. Orlowski RZ, Vorrhess PM, Garcia RA, et al. Phase 1 trial of the proteasome inhibitor bortezomib and pegylated liposomal doxorubicin in patients with advanced hematologic malignancies. Blood. 2005; 105:3058-3065.

46. Cusack JC, Liu R, Houston M, et al. Enhanced chemosensitivity to CPT-11 with proteasome inhibitor PS-341: Implications for systemic nuclear factor-k B inhibition. Cancer Res. 2001;61:3535-3540.

47. Ma MH, Yang HH, Parker K, et al. The proteasome inhibitor PS-341 markedly enhances sensitivity of multiple myeloma tumor cells to chemotherapeutic agents. Clin Cancer Res. 2003;9:1136-1144.

48. Wang M, Han XH, Zhang L, et al. Bortezomib is synergistic with rituximab and cyclophosphamide in inducing apoptosis of mantle cell lymphoma cells in vitro and in vivo. Leukemia. 2008;22:179-185.

49. Olejniczak SH, Blickwedehl J, Belicha-Villaneuva A, et al. Distinct molecular mechanisms responsible for bortezomib-induced death of therapy-resistant versus -sensitive B-NHL cells. Blood. 2010;116:5605-5614

50. Richardson PG, Mitsiades C, Hideshima T, Anderson KC. Proteasome inhibition in the treatment of cancer. Cell Cycle. 2005;4:29-296.

51. Yang HH, Ma MH, Vescio RA, Berenson JR. Overcoming drug resistance in multiple myeloma: the emergence of therapeutic approaches to induce apoptosis. J Clin Oncol. 2003;21:4239-4247.

52. Ribrag V, Gisselbrecht C, Haloun C, et al. Efficacy and toxicity of 2 schedules of frontline rituximab plus cyclophosphamide, doxorubicin, vincristine, and prednisone plus bortezomib in patients with B-cell lymphoma: a randomized Phase 2 trial from the French Adult Lymphoma Study Group (GELA). Cancer. 2009;115:4540-4546.

53. Leonard JP, Furman RR, Cheung YK, et al. CHOP-R + bortezomib as initial therapy for diffuse large B-cell lymphoma (DLBCL) [Abstract]. J Clin Oncol. 2007;25:18S.

54. Sehn LH, MacDonald D, Rubin S, et al. Bortezomib added to R-CVP is safe and effective for previously untreated advanced-stage follicular lymphoma: a Phase II study by the National Cancer Institute of Canada Clinical Trials Group. J Clin Oncol. 2011;29:3396-3401.

55. Marcus R, Imrie K, Blech A, et al. CVP chemotherapy plus rituximab compared with CVP as first-line treatment for advanced follicular lymphoma. Blood. 2005;105:1417-1423.

56. Rummel MJ, Al-Batran SE, Kim S, et al. Bendamustine plus rituximab is effective and has a favorable toxicity profile in the treatment of mantle cell and low-grade non-Hodgkin's lymphoma. J Clin Oncol. 2005;23:3383-3389.

57. Robinson KS, Williams ME, va der Jagt RH, et al. Phase II multicenter study of bendamustine plus rituximab in patients with relapsed indolent B-cell and mantle cell non-Hodgkin's lymphoma. J Clin Oncol. 2008;26:4473-4479.

58. Fowler N, Kahl BS, Lee P, et al. Bortezomib, bendamustine, and rituximab in patients with relapsed or refractory follicular lymphoma: The Phase II VERTICAL study. J Clin Oncol. 2011;29:1-9.

59. Friedberg JW, Vose JM, Kelly JL, et al. The combination of bendamustine, bortezomib, and rituximab for patients with relapsed/ refractory indolent and mantle cell non-Hodgkin lymphoma. Blood. 2011;117:2807-2812.

60. Mateos M, Oriol A, Martinez-Lopez J, et al. Bortezomib, melphalan, and prednisone versus bortezomib, thalidomide, and prednisone as induction therapy followed by maintenance treatment with bortezomib and thalidomide versus bortezomib and prednisone in elderly patients with untreated multiple myeloma: a randomised trial. Lancet Oncol. 2010;11:934-941.

61. Cavaletti G, Jakubowiak AJ. Peripheral neuropathy during bortezomib treatment of multiple myeloma: a review of recent studies. Leuk Lymphoma. 2010;51:1178-1187.

62. Delforge M, Blade J, Dimopoulos MS, et al. Treatment-related peripheral neuropathy in multiple myeloma: the challenge continues. Lancet Oncol. 2010;11:1086-1095.

63. Richardson PG, Briemberg H, Jagannath S, et al. Frequency, characteristics, and reversibility of peripheral neuropathy during treatment of advanced multiple myeloma with bortezomib. J Clin Oncol. 2006;24:3113-3120. 
64. Richardson PG, Sonneveld P, Schuster MW, et al. Reversibility of symptomatic peripheral neuropathy with bortezomib in the Phase III APEX trial in relapsed multiple myeloma: impact of a dose-modification guideline. Br J Haematol. 2009;144:895-903.

65. Salles $\mathrm{G}$. Is there a role for bortezomib combinations in the management of patients with follicular lymphoma? J Clin Oncol. 2011;29:1-2.

66. Moreau P, Pylypenko H, Grosicki S, et al. Subcutaneous versus intravenous administration of bortezomib in patients with relapsed multiple myeloma: a randomised, Phase 3, non-inferiority study. Lancet Oncol. 2011;12:431-440.

67. Beaven AW, Shea TC, Moore DT, et al. A Phase I study evaluating ibritumomab tiuxetan (Zevalin) in combination with bortezomib (Velcade) in relapsed/refractory mantle cell and low grade B-cell non-Hodgkin lymphoma. Leuk Lymphoma. 2012;53:254-258.
68. Wright JJ. Combination therapy of bortezomib with novel targeted agents: an emerging treatment strategy. Clin Cancer Res. 2010;16: 4094-4104.

69. Czuczman MS, Grillo-Lopez AJ, White CA, et al. Treatment of patients with low-grade B cell lymphoma with the combination of chimeric antiCD20 monoclonal antibody and CHOP chemotherapy. J Clin Oncol. 1999; 17:268-276.

70. Rummel MJ, Niederle N, Maschmeyer G, et al. Bendamustine plus rituximab is superior in respect of progression free survival and CR rate when compared to CHOP plus rituximab as first-line treatment of patients with advanced follicular, indolent, and mantle cell lymphomas: final results of a randomized Phase III Sstudy of the StiL (Study Group Indolent Lymphomas, Germany). Blood. 2009;114:Abstract 405.

\section{Publish your work in this journal}

Patient Preference and Adherence is an international, peer-reviewed, open access journal focusing on the growing importance of patient preference and adherence throughout the therapeutic continuum. Patient satisfaction, acceptability, quality of life, compliance, persistence and their role in developing new therapeutic modalities and compounds to optimize clinical outcomes for existing disease states are major areas of interest. This journal has been accepted for indexing on PubMed Central. The manuscript management system is completely online and includes a very quick and fair peer-review system. Visit http://www.dovepress.com/ testimonials.php to read real quotes from published authors.

Submit your manuscript here: http://www.dovepress.com/patient-preference-and-adherence-journal 